UNIVERSIDADE DE SÃO PAULO

FACULDADE DE ODONTOLOGIA DE BAURU

VANESSA SVIZZERO FAKHOURY

Evaluation of Myrcia bella in murine osteosarcoma cells: effect of the crude extract and fractions of ellagitannins and flavonoids

Avaliação de Myrcia bella em células de osteossarcoma murino: efeito do extrato bruto e frações de elagitaninos e flavonoides 

Evaluation of Myrcia bella in murine osteosarcoma cells: effect of the crude extract and fractions of ellagitannins and flavonoids

\title{
Avaliação de Myrcia bella em células de osteossarcoma murino: efeito do extrato bruto e frações de elagitaninos e flavonoides
}

\author{
Dissertação constituída por artigo \\ apresentada à Faculdade de Odontologia \\ de Bauru da Universidade de São Paulo \\ para obtenção do título de Mestre em \\ Ciências no Programa de Ciências \\ Odontológicas Aplicadas, na área de \\ concentração Estomatologia e Biologia \\ Oral. \\ Orientador: Prof. Dr. Rodrigo Cardoso de \\ Oliveira
}


Fakhoury, Vanessa Svizzero

Evaluation of Myrcia bella in murine osteosarcoma cells: effect of the crude extract and fractions of ellagitannins and flavonoids / Vanessa Svizzero Fakhoury - Bauru, 2020.

71 p. : il. ; $31 \mathrm{~cm}$.

Dissertação (Mestrado) - Faculdade de Odontologia de Bauru, Universidade de São Paulo, 2020.

Orientador: Prof. Dr. Rodrigo Cardoso de Oliveira

Autorizo exclusivamente para fins acadêmicos e científicos, a reprodução total ou parcial desta dissertação/tese, por processos fotocopiadores e outros meios eletrônicos.

Assinatura:

Data: 
ERRATA 

FOLHA DE APROVAÇÃO 



\section{DEDICATÓRIA}

A Deus, pela minha vida e por tudo o que ela me proporciona.

Ao meus pais, Eduardo e Elenice e minha irmã Renata pelo amor e carinho incondicional. Por sempre estarem ao meu lado, me apoiando e incentivando em todos os momentos de minha vida. Dedico tudo isso a vocês.

A todos os amigos de pesquisa e laboratório que sempre me acolheram tão bem e tanto me ajudaram durante meu mestrado. 



\section{AGRADECIMENTOS}

Agradeço primeiramente a Deus, por tudo! Por mais uma etapa concluída com sucesso em minha vida. Por me dar forças, saúde e alegria todos os dias para enfrentar mais um dia de vida. Obrigada!

Aos meu pais e minha irmã por serem a melhor família que eu poderia ter. Por nós estarmos sempre unidos e eles me darem forças para eu continuar em qualquer projeto de minha vida. Amo vocês do fundo do meu coração.

Aos meus amigos da cultura celular Dri, Ana, Cintia, Gabi, Mari, Kelly e Adriana! Por me auxiliarem nos experimentos e sempre me ajudarem nos momentos que eu mais precisei, pelas inesquecíveis risadas e pelos momentos maravilhosos que tivemos juntos. Em especial agradeço a Cintia e ao Adriano por tanto conhecimento transmitido e pela paciência ao me ensinarem tudo o que aprendi. Podem ter certeza que a bagagem é gigante e será muito bem utilizada. Obrigada de coração por tudo, carrego todos vocês em um lugar especial!

Ao meu orientador professor Rodrigo, pela orientação e incentivo que me deu desde o princípio. Por ser sempre tão atencioso e prestativo com todas as minhas dúvidas e questionamentos. Por acreditar em mim e me ajudar o que tanto objetivei ao chegar na FOB-USP. Obrigada imensamente pela confiança.

Aos amigos que o laboratório me deu Vini, Line, Tatá, Na, Ta, Even, Nath, Ju... Foi tão incrível compartilhar minha rotina com vocês! Obrigada pela amizade, pelas risadas, momentos de relax enquanto o laboratório estava naquela correria, pelas ajudas, saídas e por eu sempre poder contar com vocês.

A Lari e a Thel pelas conversas, orientações e todos os conhecimentos transmitidos que vocês passaram a mim! Obrigada por tantos conselhos e ajudas quando mais precisei. Só tenho a agradecer vocês.

Aos professores da disciplina de Bioquímica Ana Carolina Magalhães, Marília Afonso Rabelo Buzalaf e Rodrigo Cardoso de Oliveira. Obrigada pelos valiosos ensinamentos e atenção para com todos os alunos. 

Aos colaboradores Anne Lígia Dokkedal, Luiz Leonardo Saldanha e Fernanda Melo da Universidade Estadual Paulista Júlio de Mesquita Filho - UNESP, pela ajuda na realização deste estudo.

A secretária do Departamento Dalva Ribeiro de Oliveira, por ser sempre tão solícita. Por toda ajuda, apoio e orientações. Obrigada por toda atenção prestada à mim e aos demais alunos da pós.

A todas as pessoas que de forma direta ou indireta contribuíram para a realização deste trabalho, deixo os meus sinceros agradecimentos.

Agradeço a Fundação de Amparo à Pesquisa do Estado de São Paulo FAPESP pela bolsa de pesquisa concedida, processo $n^{\circ} 2017 / 26261-6$. A bolsa concedida pela instituição de fomento foi indispensável para que a pesquisa alcançasse os resultados aqui apresentados.

O presente trabalho foi realizado com o apoio da Coordenação de Aperfeiçoamento de Pessoal de Nível Superior - Brasil (CAPES) - Código de Financiamento 001.

Agradeço também a faculdade de Odontologia de Bauru-FOB/USP por ter utilizado as dependências da instituição e todos os equipamentos para a realização deste projeto de mestrado. 

“Vá firme na direção das suas metas, porque o pensamento cria, o desejo atrai e a fé realiza". 



\section{RESUMO}

O osteossarcoma (OS) é o tipo mais comum de câncer que se desenvolve nos ossos, caracterizado pela formação de osteócitos anormais. Os fitoquímicos estão surgindo consistentemente no campo da saúde médica com implicações terapêuticas promissoras, devido à resistência aos medicamentos na taxa de cura na quimioterapia em osteossarcoma. As plantas medicinais compõem parte da biodiversidade e são abundantemente utilizadas desde a existência da humanidade. Entre as espécies medicinais de destaque do cerrado, encontra-se a Myrcia bella Cambess, da família Myrtaceae. Estudos demonstram que espécies do gênero Myrcia têm sido utilizadas na medicina popular como adstringentes, diuréticos, no estancamento de hemorragias, tratamento de hipertensão e diabetes mellitus e também contra células de tumor gástrico. Estudos de fitoquímica do extrato hidroalcoólico das folhas de Myrcia bella (MB) revelaram uma grande quantidade de heterosídeos de flavonoides acetilados derivados de quercetina e miricetina, além de taninos derivados de ácido elágico e ácido gálico. Deste modo, MB tem demonstrado um promissor potencial contra diversas alterações patológicas, sendo necessário o entendimento de sua ação e confirmação de concentrações seguras. Assim, o presente estudo avaliou os efeitos de MB sobre células tumorais de osteossarcoma UMR-106 (in vitro). Foram realizados os ensaios de viabilidade celular em diferentes concentrações do extrato bruto (CE) de folhas de MB e frações de elagitanino (ELT) e flavonoide (FV) utilizando a célula diferenciada osteoblástica MC3T3-E1 como controle e, após determinadas as concentrações, foi avaliado o potencial migratório, produção de espécies reativas de oxigênio $(R O S)$ das células e ensaios para verificar a atividade de metaloproteinases de matriz (MMP) -2 e -9 no período de 48h. Os resultados em UMR-106 mostraram que CE $80 \mu \mathrm{g} / \mathrm{mL}$, ELT $160 \mu \mathrm{g} / \mathrm{mL}$ e FV $64 \mu \mathrm{g} / \mathrm{mL}$ reduziram a viabilidade celular $(p<0,05)$. Além disso, CE e FV inibiram a migração celular, diminuíram a produção de ROS e reduziram a atividade de MMP-2 e 9. A partir dos resultados obtidos, o CE e principalmente o FV apresentaram atividade antioxidante e efeito citotóxico sobre a linhagem celular testada.

Palavras-chave: Myrcia bella. Planta medicinal. Viabilidade Celular. Osteossarcoma. 



\section{ABSTRACT \\ Evaluation of Myrcia bella in murine osteosarcoma cells: effect of the crude extract and fractions of ellagitannins and flavonoids.}

Osteosarcoma (OS) is the most common type of cancer that develops in bone tissue, characterized by the formation of abnormal osteocytes. Phytochemicals are consistently emerging in the medical health field with promising therapeutic implications, due to drug resistance in the cure rate for chemotherapy in osteosarcoma. Medicinal plants make up part of biodiversity and have been used extensively throughout the existence of mankind. Among the medicinal species of note in the Cerrado is Myrcia bella Cambess, from the Myrtaceae family. Studies show that species of the genre Myrcia have been used in folk medicine as astringents, diuretics, in stopping bleeding, treating hypertension and diabetes mellitus and also against gastric tumor cells. Phytochemical studies of the hydroalcoholic extract of the leaves of Myrcia bella (MB), revealed a large amount of acetylated flavonoid heterosides derived from quercetin and myricetin, in addition to tannins derived from ellagic acid and gallic acid. Thus, MB has demonstrated a promising potential against several pathological alterations, requiring the understanding of its action and confirmation of safe concentrations. This study evaluated the effects of MB on UMR-106 osteosarcoma tumor cells (in vitro). Cell viability tests were carried out at different concentrations of crude extract (CE) of MB leaves and ellagitannin (ELT) and flavonoid (FV) fractions using the MC3T3-E1 differentiated osteoblastic cell as a control, and then determined concentrations, evaluated the migratory potential, production of reactive oxygen species from the cells (ROS) and assays to verify the activity of matrix metalloproteinases (MMP) -2 and -9 in the period of $48 \mathrm{~h}$. The results in UMR-106 showed that CE $80 \mu \mathrm{g} / \mathrm{mL}$, ELT $160 \mu \mathrm{g} / \mathrm{mL}$ and FV $64 \mu \mathrm{g} / \mathrm{mL}$ reduced cell viability $(p<0.05)$. In addition, CE and FV inhibited cell migration, decreased ROS production and reduced MMP-2 and 9 activity. From the results obtained, CE and mainly FV showed antioxidant activity and cytotoxic effect on the tested cell line.

Keywords: Myrcia bella. Medicinal plants. Cell Viability. Osteosarcoma. 

SUMÁRIO

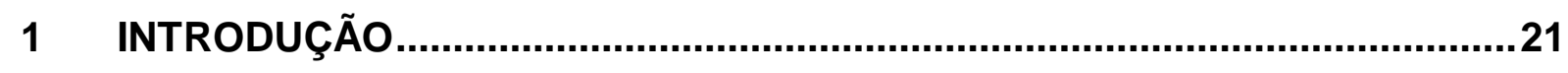

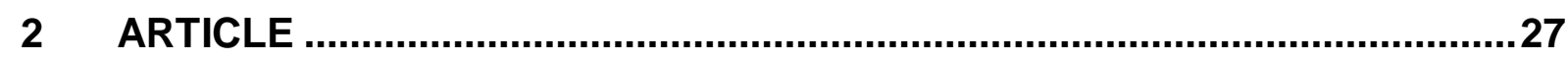

3 DISCUSSÃO

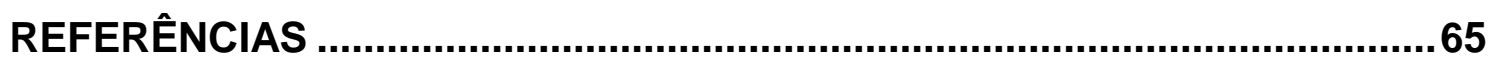

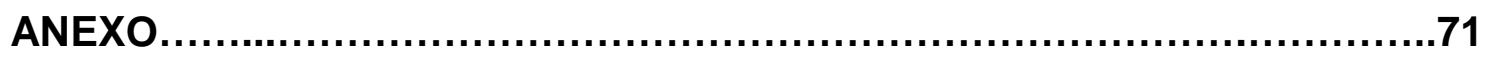



1 INTRODUÇÃO 



\section{INTRODUÇÃO}

O osteossarcoma (OS), tipo mais comum de câncer ósseo, é o mais frequente tumor mesenquimal maligno causado por alterações genéticas e epigenéticas que interrompem a diferenciação de osteoblastos provenientes de células tronco mesenquimais, com alto potencial de destruição local e metástase (MATOS, 2017). Em geral, a incidência de OS na população é maior na adolescência, cuja incidência anual atinge um pico de 8 a 11 milhões por ano na faixa etária entre 15 e 19 anos de idade (RITTER; BIELACK, 2010).

Como os osteoblastos no osso normal, as células que formam este tipo de câncer produzem a matriz óssea, entretanto essa matriz não é tão forte quanto a dos ossos normais (CORREIA et al., 2013). Embora a incidência global desta neoplasia não seja alta, o osteossarcoma é um dos mais frequentes tumores associados com outras doenças malignas, sendo sua etiologia multifatorial e a incidência maior ocorre em crianças e jovens (AMERICAN CANCER SOCIETY, 2019).

Dentro desse contexto, algumas enzimas, como as metaloproteinases de matriz (MMPs), se destacam por apresentarem algum papel no desenvolvimento ou progressão de neoplasias. As metaloproteinases de matriz são uma família de enzimas zinco-dependentes que degradam a matriz extracelular, consideradas como importantes facilitadoras para a invasão e disseminação tumoral (JUCÁ et al., 2008).

Devido à resistência aos medicamentos na taxa de cura na quimioterapia com osteossarcoma, há uma necessidade urgente de terapêutica melhorada/apurada, afim de atenuar ou superar a quimiorresistência, pois contribuirá significativamente para o tratamento da doença (XU, 2016).

Existem vários alopáticos eficazes e opções de tratamento disponíveis no mercado, mas todos apresentam algum tipo de efeito colateral. Portanto, há a necessidade de estratégias terapêuticas alternativas que possam não apenas melhorar o potencial terapêutico, mas também reduzir possíveis efeitos adversos. A busca por fitoquímicos aumentou devido ao seu potencial uso na terapia como antioxidantes ou drogas anticâncer, com implicações terapêuticas promissoras. Entre eles, os compostos fenólicos formam o grupo principal. Uma classe de compostos bioativos, os flavonoides, foram testados contra várias doenças humanas, incluindo câncer, doenças cardiovasculares, diabetes, distúrbios neurológicos entre outras. Em 
vários cânceres humanos, os flavonoides são conhecidos como compostos eficazes por seu papel fundamental na apoptose, ciclo celular, angiogênese, metástase, inflamação e estresse oxidativo (KASHYAP et al., 2019; SANTOS et al., 2018).

Recentemente, o interesse pelos flavonoides tem aumentado devido a sua gama de efeitos farmacológicos, e a sua capacidade de inibir a atividade de algumas enzimas, além da sua atividade antioxidante. Os efeitos dos flavonoides são reconhecidos como potenciais candidatos para serem utilizados no tratamento de diversas doenças, como câncer, arteriosclerose, doenças cardiovasculares, neurodegenerativas como Parkinson e Alzheimer e doenças relacionadas com a idade. Todos os efeitos dos flavonoides estão parcialmente associados às propriedades de sequestro de radicais livres (SALDANHA, 2013). Estes compostos fenólicos são classificados por muitos estudos como inibidores de câncer por manifestar atividades antioxidantes, controlar a proliferação celular, bloquear a angiogênese, modular enzimas do metabolismo carcinogênico e detoxificação de carcinógenos (PEREIRA et al., 2015).

Dentre as diversas plantas existentes no Brasil, uma das espécies que tem despertado interesse é a Myrcia bella Cambess (Myrtaceae), popularmente conhecida como "mercurinho", uma espécie comum e importante em muitos fragmentos do cerrado, distribuídos no estado de São Paulo. A Myrtaceae é uma família importante no cerrado brasileiro, muitas delas com atividades biológicas relatadas. O gênero Myrcia pertence a uma classe fitoquímica de elevada importância terapêutica (SALDANHA, 2013).

Estudos de fitoquímica do extrato hidroalcoólico das folhas de Myrcia bella, revelaram uma grande quantidade de heterosídeos de flavonoides acetilados derivados de quercetina e miricetina (SALDANHA; VILEGAS; DOKKEDAL, 2013), além de taninos derivados de ácido elágico e ácido gálico, o que atribui a esta espécie um grande potencial medicinal (MELO; DOKKEDAL; SALDANHA, 2017).

Espécies do gênero Myrcia têm sido utilizadas na medicina popular como adstringentes, diuréticos, tratamento do diabetes mellitus, estancamento de hemorragias e no tratamento de hipertensão e úlceras (VAREDA, 2013).

Na família Myrtaceae, os fenólicos são os metabólitos secundários mais abundantes nas plantas e suas espécies têm a capacidade de acumulá-los. Esses compostos orgânicos são importantes antioxidantes de defesa sendo mais potentes que a vitamina C, E e os carotenoides (TAKAO; IMATOMIB; GUALTIERIA, 2015). 
Para muitos grupos étnicos e comunidades, o conhecimento sobre plantas medicinais simboliza, na maioria das vezes, o único recurso terapêutico, sendo comercializadas livremente em feiras ou mercados. Contudo, esse uso indiscriminado apresenta um alto risco, pois pouco se sabe sobre suas propriedades farmacológicas e toxicidade (RINALDO, 2010).

Dentre os requisitos fundamentais para o registro de medicamentos fitoterápicos, deve-se ter o conhecimento da composição química e da atividade farmacológica da planta, para que se possa estabelecer critérios e metodologias para análise, controle de qualidade e preparo de formulações fitoterápicas (ANVISA, 2010; SALDANHA, 2013).

Esta dissertação é apresentada na forma de um artigo, no qual avaliamos o efeito das diferentes concentrações do extrato bruto e frações de elagitaninos e flavonoides de Myrcia bella em células de osteossarcoma (in vitro). 



\section{REFERÊNCIAS}





\section{REFERÊNCIAS}

ABOTALEB, M. et al. Flavonoids in Cancer and Apoptosis. Cancers (Basel), v. 11, n. 1, 1-39, 2018.

AMERICAN CANCER SOCIETY. Osteosarcoma, 2016. Disponível em: https://www.cancer.org/cancer/osteosarcoma.html. Acesso em: 04 Dez 2019.

ANVISA. AGÊNCIA NACIONAL DE VIGILÂNCIA SANITÁRIA. Boas Práticas de Fabricação de Medicamentos - RDC no 17, de 16 de Abril de 2010. Disponível em: http://portal.anvisa.gov.br/registros-e-autorizacoes/medicamentos/empresas/boaspraticas-fabricacao. Acesso em: 10 Dez 2019.

BARREIROS, A. L. B. S.; DAVID, J. M.; DAVID, J. P. Estresse oxidativo: relação entre geração de espécies reativas e defesa do organismo. Química Nova, v. 29, p. 113-123, 2006.

BEHLING, E. B. et al. Flavonóide quercetina: aspectos gerais e ações biológicas. Alim. Nutr., v. 15, n. 3, p. 285-292, 2004.

BERNDT, K. et al. Evaluation of quercetin as a potential drug in osteosarcoma treatment, Anticancer Res., v. 33, p. 1297-1306, 2013.

BJØRNLAND, K. et al. Matrix Metalloproteinases Participate in Osteosarcoma Invasion. Journal of Surgical Research, v. 127, n. 2, p. 151-156, 2005

BRANDAO, H. N. et al. Química e farmacologia de quimioterápicos antineoplásicos derivados de plantas. Química Nova, v. 33, n. 6, p. 1359-1369, 2010.

BUDOVSKY, A.; YARMOLINSKY, L.; BEN-SHABAT, S. Effect of medicinal plants on wound healing. Wound Repair and Regeneration, v. 23, n. 2, p. 171-183, 2015.

BUYEL, J. F. Plants as sources of natural and recombinant anti-cancer agents. Biotechnology Advances, v. 36, p. 506-520, 2018.

CALIXTO, J.B. Biodiversidade como fonte de medicamentos. Cienc. Cult., v. 55, n. 3, p. 37-39, 2003.

CASCAES, M. M. et al. Constituents and Pharmacological Activities of Myrcia (Myrtaceae): A Review of an Aromatic and Medicinal Group of Plants. Int J Mol Sci, v. 16, n. 10, p. 23881-904, 2015.

CONEGLIAN, I. R. M. Morfoanatomia de ovário, pericarpo e semente de sete espécies de Myrteae DC. (Myrtaceae). 2011. 107 f. Tese (doutorado) Universidade Estadual Paulista, Instituto de Biociências, Botucatu, 2011.

CORREIA, A. et al. Metástase cerebral de osteossarcoma: relato de caso e revisão de literatura. Rev. Med. Res., v.15, n.2, p.143-147, 2013. 
DO THI, N.; HWANG, E. S. Effects of laver extracts on adhesion, invasion, and migration in SK-Hep1 human hepatoma cancer cells. Bioscience, biotechnology, and biochemistry, v. 78, n. 6, p. 1044-1051, 2014.

ENDE, C.; GEBHARDT, R. Inhibition of Matrix Metalloproteinase-2 and -9 Activities by Selected Flavonoids. Planta Med., v. 70, p. 1006-1008, 2004.

GEZICI, S.; SEKEROGLU, N. Current Perspectives in the Application of Medicinal Plants Against Cancer: Novel Therapeutic Agents. Anti-Cancer Agents in Medicinal Chemistry, v. 19, p. 101-111, 2019.

IMRAN, M. et al. Luteolin, a flavonoid, as an anticancer agent: A review. Biomedicine \& Pharmacotherapy, v. 112, p. 1-10, 2019.

JUCÁ, M. et al. Metaloproteinases 1 e 7 e câncer colorretal. Rev bras. coloproctol, v.28, n.3, 2008.

KASHYAP, D. et al. Flavonoids as Emerging Anticancer Agents: Current Trends and Recent Advances in Phytotherapy. In: Hardeep Singh Tuli (Eds.). Current Aspects of Flavonoids: Their Role in Cancer Treatment. Singapore: Springer, p. 91-123, 2019.

LAN, H. et al. Quercetin Inhibits Cell Migration and Invasion in Human Osteosarcoma Cells. Cell Physiol Biochem., v. 43, p. 553-567, 2017.

LI, S. et al. Quercetin suppresses the proliferation and metastasis of metastatic osteosarcoma cells by inhibiting parathyroid hormone receptor 1. Biomed Pharmacother, v. 114, p. 1-10, 2019.

LIU, H. Flavonoids Active Against Osteosarcoma: A Review of the Molecular Mechanisms Involved. Curr Pharm Des., n. 23, v. 13, p. 1993-2001, 2017.

MATOS, A. A. Avaliação do efeito antitumoral da apocinina e diapocinina em células de osteossarcoma humano. 2017. 98 f. Tese (Doutorado) - Faculdade de Odontologia de Bauru, FOB-USP, Bauru, 2017.

MATOS, A. A. et al. An extract from Myracrodruon urundeuva inhibits matrix mineralization in human osteoblastos. Journal of Ethnopharmacology, v. 237, p. 192-201, 2019.

MELO, F. P. S. R.; DOKKEDAL, A. L.; SALDANHA, L. L. Identificação de elagitaninos em Myrcia bella Cambess. por CLAE-IS-AI-EM/EMn. In: XIII Jornada Paulista de Plantas Medicinais, Faculdade de Ciências Farmacêuticas de Araraquara, Araraquara, São Paulo, 2017.

PARK, $\mathrm{H}$. et al. Myricetin treatment induces apoptosis in canine osteosarcoma cells by inducing DNA fragmentation, disrupting redox homeostasis, and mediating loss of mitochondrial membrane potential. Journal of cellular physiology, v. 233, n. 9, p. 7457-7466, 2018. 
PEREIRA, A. C. et al. O papel das MMP-2 e -9 no desenvolvimento do carcinoma epidermóide. Revista Brasileira de Cancerologia, v. 52, n. 3, p. 257-262, 2006.

PEREIRA, W. L. et al. Ação antiproliferativado flavonoide morina e do extrato da folha de oliveira (Oleaeuropaea L.) contra a linhagem de célula H460. Rev. Bras. PI. Med., v. 17, n. 4, supl. I, p. 798-806, 2015.

POPOLIN, C. P. Efeitos antitumorais e antimetastáticos de novos complexos de rutênio em células de câncer de mama. 2016. 66 f. Dissertação (Mestrado) Curso de Ciências Fisiológicas, Universidade Federal de São Carlos - UFSCAR, São Carlos, 2016.

RINALDO, D. Determinação de enantiômeros em extratos vegetais por cromatografia quiral e dicroísmo circular. 2010. 105 f. Tese (Doutorado) - Curso de Química, Instituto de Química, Universidade Estadual Paulista - Unesp Araraquara, Araraquara, 2010.

RITTER, J.; BIELACK, S. S. Osteosarcoma. Annais of Oncology, v. 21, p. 320325, 2010.

SALDANHA, L. L. Prospecção química e avaliação das atividades antioxidante e alelopática de Myrcia bella Cambess. 2013. 161 f. Dissertação (Mestrado) Instituto de Biociências de Botucatu, Universidade Estadual Paulista "Julio de Mesquita Filho", Botucatu, 2013.

SALDANHA, L. L.; VILEGAS, W.; DOKKEDAL, A. L. Characterization of Flavonoids and Phenolic Acids in Myrcia bella Cambess. Using FIA-ESI-IT-MSn and HPLCPADESI-IT-MS Combined with NMR. Molecules, v. 18, p. 8402-8416, 2013.

SALEHI, B. et al. Phytotherapeutics in cancer invasion and metastasis. Phytotherapy Research, v. 32, n. 8, p. 1425-1449, 2018.

SANTOS, C. et al. Antioxidative, Antiproliferative and Antimicrobial Activities of Phenolic Compounds from Three Myrcia Species. Molecules, v. 23, n. 986, p. 1-12, 2018.

SARAGUSTI, A. C. et al. Inhibitory effect of quercetin on matrix metalloproteinase 9 activity Molecular mechanism and structure-activity relationship of the flavonoidenzyme interaction. European Journal of Pharmacology, n. 644, p. 138-145, 2010.

SERPELONI, J. M. et al. Antimutagenicity and induction of antioxidant defense by flavonoid rich extract of Myrcia bella Cambess. in normal and tumor gastric cells. Journal of Ethnopharmacology, v. 176, p. 345-355, 2015.

SCHERER, R.; GODOY, H. T. Antioxidant activity index (AAI) by the 2,2-diphenyl-1picrylhydrazyl method. Food Chemistry, v. 112, n. 3, p. 654-658, 2009.

TAKAO, L.K.; IMATOMIB, M.; GUALTIERIA, S. C. J. Antioxidant activity and phenolic content of leaf infusions of Myrtaceae species from Cerrado (Brazilian Savanna).

Braz. J. Biol, v. 75, n. 4, p. 948-952, 2015. 
VAREDA, P. M. P. Avaliação da atividade hipoglicemiante do extrato de Myrcia bella em camundongos diabéticos induzidos por estreptozotocina. 2013. $81 \mathrm{f}$. Dissertação (Mestrado) - Instituto de Biociências de Botucatu, Universidade Estadual Paulista "Júlio de Mesquita Filho", Botucatu, 2013.

VAREDA, P.M.P. et al. Myrcia bella leaf extract presents hypoglycemic activity via $\mathrm{PI}$ KK/Akt insulin signaling pathway. Evidence-Based Complementary and Alternative Medicine, n. 2014, p. 1-11, 2014.

XU, H. (Z)-3,4,3',5'-tetramethoxystilbene, a natural product, induces apoptosis and reduces viability of paclitaxel-and cisplatin-resistant osteosarcoma cells. J Cancer Res Ther, v. 12, n. 4, p. 1261-1265, 2016. 
ANEXO 



\section{Participação em encontro científico}

Nome do evento: Reunión Anual de SOCIEDADES DE BIOCIENCIA SAIC. SAIFE. SAB. SAP. AACYTAL. NANOMED-ar. HCS. Mar del Plata, Argentina, November 13th to 19 th, 2019.

Apresentação de trabalho em forma de pôster: "Evaluation of Myrcia bella in murine osteosarcoma cells: effect of the crude extract and fractions of ellagitannins and flavonoids“. FAKHOURY, V. S.; PESSOA, A. S.; PAGNAN, A. L.; TOKUHARA, C. K.; OLIVEIRA, G. S. N.; LIESSA, M. R. S.; SALDANHA, L. L.; DOKKEDAL, A. L.; OLIVEIRA, R. C.

"Cytotoxicity of methyl vanillate and methyl divanillate in breast cancer cells". PESSOA, A. S.; TOKUHARA, C. K.; PAGNAN, A. L.; FAKHOURY, V. S.; LIESSA, M. R. S.; OLIVEIRA, G. S. N.; XIMENES, V. F.; OLIVEIRA, R. C.

"Increased resistance of MC3T3-E1 cells differentiated or not compared to UMR-106 in response to Caffeic Acid and Caffeic Acid Phenethyl Ester (CAPE)". PAGNAN, A. L.; PESSOA, A. S. ; FAKHOURY, V. S.; TOKUHARA, C. K.; LIESSA, M. R. S.; OLIVEIRA, G. S. N.; XIMENES, V. F.; OLIVEIRA, R. C. 